\title{
FATORES QUE INTERFEREM NA PRESERVAÇÃO DO SONO E REPOUSO DE CRIANÇA EM TERAPIA INTENSIVA
}

\author{
Factors that interfere on sleep and rest of the child \\ in the intensive care therapy \\ Factores que interfieren en la preservación del sueño \\ y reposo del niño en terapia intensiva
}

\begin{abstract}
Resumo
Trata-se de um estudo de caso com uma criança internada em Unidade de Terapia Intensiva Pediátrica, cujo objetivo é descrever os fatores que interferem na preservação de seu sono e repouso. Utilizou-se como método, para a coleta de dados, observação direta, a partir dos procedimentos realizados e da maneira de cuidar da criança pela equipe multiprofissional. Os resultados denotam que o sono e o repouso foram interrompidos em intervalos de 25 minutos, evidenciando a necessidade e a privatização do sono e repouso nestas circunstâncias. Conclui-se que a assistência à criança que necessita de cuidados intensivos deve estar voltada para atender suas necessidades individuais, utilizando para tal uma abordagem humanística que implica na formação de conjuntos, na interdisciplinaridade dos profissionais, buscando a integralidade, a unicidade e a interdependência.
\end{abstract}

Palavras-chave: Enfermagem Pediátrica. Cuidados intensivos. Sono. Repouso.

\begin{abstract}
This study focused the case of a child admitted to hospital in an Intensive Therapy Paediatrics Unit, to identify factors that interfere on his sleep and rest. We used as method for data collection the participant observation, over the procedures done and the way of the child care in the multiprofessional team. The results denote that sleep and rest were interrupted in 25 minutes intervals, showing the need and the deprive of the sleep under those circumstances. We concluded that the assistance of children who needs intensive care must be looking for their individual necessities using for that an humanistic approach which implies in joints formation, professional interdisciplinarity, searching the wholeheartedly, the unit and interdependence.
\end{abstract}

Keywords:

Pediatric Nursing. Intensive Care. Sleep. Rest.

\section{Resumen}

Estudio de caso con un niño internado en Unidad de Terapia Intensiva Pediátrica, cuyo objetivo es describir los factores que interfieren en la preservación de su sueño y reposo. Se utilizó como método, para la colecta de datos, la observación directa, a partir de los procedimientos realizados y de la manera de cuidar del niño por el equipo profesional. Los resultados denotan que el sueño y el reposo fueron interrompidos en intervalos de 25 minutos, evidenciando la necesidad y la privatización del sueño y reposo en estas circunstancias. Se concluye que la asistencia al niño que necesita de cuidados intensivos debe estar dirigida para atender sus necesidades individuales utilizando una abordaje humanística que implica en la formación de conjuntos, en la interrelación de disciplinas de los profesionales, buscando la integralidad, la unicidad y la interdependencia. 


\section{INTRODUÇÃO}

A busca de qualidade para a prestação da assistência ao cliente de alta complexidade em tratamento intensivo nos conduz à reflexão e ao debate acerca de temas emergentes das práticas profissionais, geralmente vividos no cotidiano do trabalho dos enfermeiros, e que constituem motivo de inquietação para esses profissionais. Essa reflexão torna-se ainda mais evidente quando a qualidade do cuidado está relacionada à criança submetida a tratamento intensivo, primordial à sua recuperação. Cuidado este voltado principalmente para proporcionarIhe um ambiente terapêutico com condições tais que favoreçam o tratamento e, conseqüentemente, a cura.

Entendemos que a prática sistematizada do cuidar, incorporada a novas formas de conhecimento, proporciona o desenvolvimento e a autonomia profissional, pois o cuidado é a essência da prática profissional do enfermeiro ${ }^{1}$. Com esse entendimento, 0 cuidado de enfermagem em pediatria deve considerar a criança na sua dimensão física, social, biológica, espiritual, emocional. E o enfermeiro, como 0 agente desse cuidado, deve criar condições tais que possibilitem ao cliente receber 0 cuidado de forma abrangente, utilizandose de todos os sentidos, da forma mais terna, segura e serena, de modo que o produto dessa ação possa resultar em conforto, bem-estar, alívio e satisfação ?

Assim, defendemos a idéia de que o cuidado jamais deve ser visto simplesmente como técnico e mero cumprimento de rotinas, mas como algo muito mais profundo e transformador, tanto do ponto de vista de quem cuida, como de quem é cuidado. Nesse sentido, temos o mesmo entendimento de que existe muita preocupação no desempenho de rotinas e tarefas, mas que 0 não envolvimento no modo de cuidar torna 0 cuidado difícil e inadequado $0^{3}$. Considerando que, em várias situações, se torna necessário a intensificação de procedimentos e técnicas, acredita-se que isto não implica, necessariamente, que a criança seja constantemente manuseada e conseqüentemente interrompida no seu sono e repouso.

Acreditamos que existam situações nas quais seja perfeitamente possível priorizar o que for mais importante para a criança naquele momento - nessas condições é primodial que 0 sono e o repouso sejam respeitados, pois são fundamentais para a saúde e tão importantes quanto a alimentação ${ }^{4}$. Dessa forma, 0 sono constitui fator necessário e inprescindivel, sendo, inclusive, referido como direito universal do ser humano, já que todos precisam dormir 5 . Entendemos, também, que o Centro de Terapia Intensiva (CTI), embora ofereça cuidados especializados, com observação constante e equipamentos oriundos de tecnologias avançadas e de alta precisãa ${ }^{6}$, talvez seja o local que mais gera estresse nos clientes e em seus familiares.
Na trajetória que nos conduz à UTIP, temos observado que, quando a criança é excessivamente manuseada, se desencadeia um quadro respiratório agudo, caracterizado por taquipnéia, esforço respiratório e sudorese acompanhada de intensa irritabilidade 2 . Certa vez, ao sugerirmos à equipe médica que deixasse a criança descansar, com o intuito de verificar se, após o descanso, haveria melhora daquele quadro, antes de se optar por uma intubação traqueal, fomos surpreendidas com a melhora do quadro, pois a criança conseguiu conciliar o sono, tornando o procedimento invasivo desnecessário.

Essas considerações conduziram-nos a algumas premissas:

- O sono e o repouso são necessários para a restauração da saúde.

- A interrupção do sono e do repuso pode interferir no processo de recuperação da saúde da criança internada em UTIP.

- É possível adotar na UTIP maneiras de cuidar que propiciem ao cliente condições de dormir e repousar.

Diante dessas premissas, delineamos para este estudo o seguinte objetivo: descrever os fatores que interferem na preservação do sono e repouso da criança em tratamento intensivo.

A importância deste estudo, portanto, reside no fato de considerarmos o sono e o repouso como necessários à recuperação da saúde, em especial a da criança gravemente enferma. E o enfermeiro, através do cuidado direto ou do indireto, relacionado ao ambiente, deve proporcionar melhores condições de sono e repouso à criança hospitalizada, interferindo assim, no processo de recuperação através do cuidado.

\section{METODOLOGIA}

Trata-se de um estudo de caso, realizado com uma criança internada na unidade de terapia intensiva pediátrica (UTIP) de um hospital público de ensino, pesquisa e assistência situado na região metropolitana do Rio de Janeiro, durante o segundo semestre de 2002.

A referida unidade atende crianças de dois dias a 12 anos de idade, consideradas graves ou com quadro clínico bastante instável que poderá levá-las a um estado crítico, necessitando, portanto, de monitoração mecânica constante. Essa monitoração se faz por meio de aparelhagem especializada, bastante sofisticada, e pela observação cuidadosa e criteriosa de médicos e enfermeiros.

A área física compõe-se de seis leitos, sendo quatro deles leitos distribuídos em área comum e dois em boxes 
individuais, que, se necessário, são destinados à criança portadora de doença infectocontagiosa ou que necessite estar acompanhada pela mãe.

Selecionamos, para este estudo, um caso clínico de interesse, entre as demais crianças internadas, de acordo com critérios previamente estabelecidos e profissionais com ela envolvidos. Para inclusão da criança no estudo, adotamos os seguintes critérios: a) não estar sob ação de medicação curarizante (agente bloqueador neuromuscular periférico), com finalidade de promover relaxamento da musculatura voluntária; b) não estar em estado de coma; c) ter passado pelo período de admissão (após o segundo dia de internação); d) estar sem previsão para alta.

Quanto aos demais sujeitos que compõem o estudo, selecionamos os profissionais que prestavam assistência direta aos clientes internados na referida UTIP nos horários em que era realizada a pesquisa.

Para a coleta de dados, adotamos a técnica de observação direta, realizada por duas das autoras deste estudo, as quais integravam o quadro de funcionários da instituição, permitindo, com certa facilidade, 0 acesso à UTIP, as informações essenciais à estrutura do construto, as condições ambientais e a categoria do profissional que prestava cuidado ao caso selecionado, incluindo as condições comportamentais da criança. Vale ressaltar que, no momento em que estava sendo realizado 0 cuidado ou outra qualquer ação, o pesquisador limitavase às observações e às anotações acerca das reações manifestadas pela criança no diário de campo.

Os dados foram coletados em dois momentos distintos: em horário diurno e noturno, ambos com duração de 12 horas ininterruptas. Para cada um desses horários, uma das pesquisadoras acompanhava todo o procedimento realizado, sem, contudo, interferir no processo que estava sendo realizado, tanto pelo médico como pelo enfermeiro. Os dados de interesse observados e registrados no diário de campo foram: tipo de cuidado ou procedimento realizado; intervalo de um cuidado ou procedimento para outro; freqüência em que a criança era manuseada durante o turno (noturno ou diurno); se o cuidado ou procedimento era realizado em período de vigília ou em sono/repouso; duração do procedimento; se a criança conseguia dormir novamente após o manuseio; as reações que apresentava e a categoria profissional de quem realizava o cuidado.

Antes de iniciarmos a coleta de dados, solicitamos a permissão dos pais da criança selecionada para 0 estudo, mediante 0 Termo de Consentimento Livre e Esclarecido, conforme a Resolução 196/96, do Conselho Nacional de Saúde. Após esse procedimento, o projeto foi encaminhado à Comissão de Ética da Instituição, solicitando permissão para execução da pesquisa e, posteriormente, iniciarmos a fase de coleta de dados. 0 projeto foi aprovado sem restrições.

- Caso estudado

Identificação: Junior (pseudônimo)

idade: 09 meses

diagnóstico: invaginação intestinal

tempo de internação: 03 dias.

- Breve histórico: Junior deu entrada no setor três dias antes de iniciarmos nossa observação, proveniente de outra instituição onde fora operado de urgência, portando prótese respiratória, ileostomia e infusões venosas em curso. 0 seu estado de saúde apresentavase grave, com extremidades frias, torporoso e em aparente choque séptico (provavelmente devido à cirurgia). Ao iniciarmos as observações, verificamos que Junior encontrava-se acomodado em cama de adulto, do tipo Hill-rom, regulável, com válvulas acionáveis para diversas posições (Trendelenburg, Fowler e outras), contendo grades que, durante os cuidados e coleta de dados, se mantiveram abaixada.

Justificamos a preferência pelo caso Junior, dentre os demais que se encontravam em tratamento na UTIP, por entendermos que suas condições eram as que mais se aproximavam dos critérios previamente estabelecidos para inclusão no estudo.

\section{Arsenal tecnológico e demais artefatos utilizados}

Para atender às reais necessidades de Junior, encontrava-se um dispositivo de oxigênio acoplado ao respirador do tipo intermitente; dois coxins - um colocado sob a região cervical e outro sob os joelhos; aparelho de monitoração contínua não invasivo com referência para freqüência cardíaca (FC), saturação de $0_{2}$ e pressão arterial (PA); eletrodos conectados ao tórax; manguito em membro superior esquerdo (MSE); cateter intravenoso em membro superior direito (MSD) para acesso à medicação; cateter nasogástrico (SNG) em sinfonagem; saturímetro de pulso com sensor conectado no pé direito; bomba para infusão medicamentosa e hidratação venosa (HV); dois suportes - um para apoio dos frascos de soro e hidratação venosa e outro com fita (escala) para aferição de pressão venosa central (PVC); uma mesinha localizada ao lado direito da cama para apoio das bombas infusoras e o saturímetro; um carrinho de parada cardiorrespiratória (PCR), também colocado à direita da cama para eventuais necessidades; um foco de luz colocado à esquerda do leito; uma cadeira e uma lata para lixo. Na parede, havia uma fonte de $\mathrm{O}_{2}$ conectada ao ambu e uma fonte de ar comprimido com aspirador de secreção acoplado. 
A área física consta de um Box de, aproximadamente, $12 \mathrm{~m}^{2}$, localizado à esquerda, próximo à porta de entrada.Contém uma janela de vidro canelado que possibilita ampla visão e entrada de claridade externa, além da iluminação interna com lâmpadas frias, ligadas diuturnamente, situadas no teto, exatamente sobre o leito de Junior.

Após a descrição desses dados, iniciamos a investigação propriamenta dita que, conforme foi descrita anteriormente, se realizou em dois turnos distintos: sendo 0 primeiro correspondente ao horário noturno, em 12 horas ininterruptas, isto é, de 19:00 às 07:00 h, e o segundo, referente ao diurno, também correspondendo a um turno de 12 horas, de 07:00 às 19:00 h.

\section{APRESENTAÇÃO E ANÁLISE DOS RESULTADOS}

\section{Primeiro turno de observação}

período: 06/ 10/ 2002 (19h às 7h do dia seguinte).

Durante o período noturno, Junior foi seqüencialmente manuseado 10 vezes, sendo que em oito delas durante 0 sono e duas em estado de vigília. Os procedimetos mais realizados foram: exame físico feito pelo médico e enfermeira, aferição de sinais vitais, troca de curativo cirúrgico, verificação de drenagem, troca da bolsa da ileostomia, troca de roupas e fraldas, medidas de conforto e higiene (banho e acomadação no leito), exame radiológico, recolocação de eletrodos. Alguns desses procedimentos poderiam até ter sido realizados simultaneamente. Apesar de aparentemente dormindo, podemos observar no Quadro 010 número de horas de sono do Junior.

\section{Q uadro 1:}

Demonstrativo do número de horas de sono (turno 19 às $07 \mathrm{~h}$ )

\begin{tabular}{|c|c|c|}
\hline $\begin{array}{l}\text { Horário em } \\
\text { que dormiu }\end{array}$ & $\begin{array}{l}\text { Horário em que foi } \\
\text { manipulado e } \\
\text { conseqüentemente } \\
\text { acordado }\end{array}$ & $\begin{array}{c}\text { Tempo de } \\
\text { sono }\end{array}$ \\
\hline $19: 20$ & $19: 50$ & $30 \mathrm{~min}$ \\
\hline $19: 55$ & $19: 55$ & $\cdot$ \\
\hline $20: 25$ & $20: 27$ & $02 \mathrm{~min}$ \\
\hline $20: 40$ & $21: 20$ & $20 \mathrm{~min}$ \\
\hline $21: 50$ & $21: 50$ & - \\
\hline $22: 10$ & $22: 30$ & $20 \mathrm{~min}$ \\
\hline 23:00 & $23: 30$ & $30 \mathrm{~min}$ \\
\hline $00: 30$ & $02: 10$ & 01:40 h \\
\hline $02: 15$ & $02: 20$ & $05 \mathrm{~min}$ \\
\hline $02: 40$ & $05: 00$ & $02: 20 \mathrm{~h}$ \\
\hline
\end{tabular}

0 fato que mais despertou a nossa atenção para aquele momento era o manuseio intenso da criança, realizado pela equipe multiprofissional, interferindo na redução do tempo destinado ao sono e ao repouso, gerando um comportamento típico de estresse. Além disso, sabe-se que o despertar forçado dificulta o processo de reconciliação do sono após o término do manuseio, comportamento já desaprovado por Florence Nightingale, no século XIX, quando defendia a idéia de que a boa enfermeira jamais deveria permitir que um doente fosse acordado intencionalmente ou acidentalmente, pois, se fosse acordado de seu primeiro sono, dificilmente conseguiria consiliá-lo novamente, perdendo não só 0 sono, mas, também, a capacidade de dormir ${ }^{7}$.

As movimentações e/ou manuseios, que aconteceram durante o período noturno, computadas em 10 vezes, sendo que oito delas durante o sono e duas com a criança em estado de sonolência - por provável encefalopatia infecciosa (diagnóstico médico), o que o fez estar "dormindo", praticamente, durante todo o tempo. Porém, apesar dessa aparência, pudemos verificar que o número de horas que Junior dormiu foi insuficiente, pois se computou cinco horas e vinte sete minutos durante 0 período, com dez interrupções de seu sono. No entanto, nas seis vezes em que foi acordado, todas foram consideradas essenciais (troca de curativos da ileostomia, pesagem da criança, exame radiológico) e indispensáveis para a necessidade da avaliação risco-benefício, justificando, portanto, a interrupção do sono nesses momentos. Isso se deu pelo fato de a criança estar apresentando uma drenagem de secreção abundante pela ileostomia, necessitando da troca do curativo, visto que 0 acúmulo dessa secreção pode provocar lesões graves e lacerações na pele. Por esse motivo, a pesagem de Junior também se fez necessária, mesmo que seu sono fosse interrompido, contrariando a função do sono tão necessária para que o organismo possa restaurar sua capacidade física e mental. Sabe-se que a necessidade de sono da criança a partir do sexto mês de vida até um ano é de 10 a 12 horas no periodo noturno e de duas a três horas no horário diurno ${ }^{8}$.

Durante o período noturno, Junior foi manuseado 12 vezes, sendo os procedimentos executados em intervalos entre um e 60 minutos, 0 que se pode concluir que 0 intervalo de um procedimento para o outro foi em geral pequeno, menos de uma hora, na maioria das vezes com duração do procedimento, também, pequeno. Entendemos que seria mais proveitoso para Junior se os manuseios fossem mais prolongados e que pudessem ser associados cuidados de conforto com menos intervalos, o que permitiria um tempo maior de sono e repouso. 


\section{Segundo turno de observação} período: 07/ 10/ 2002 (07h às 19h).

Durante todo o horário diurno, Junior manteve-se muito sonolento - o que poderia ter ocorrido devido ao quadro clínico, acrescido da associação do opióide utilizado para alívio do quadro álgico. Na noite anterior, o seu tempo de sono não chegou a seis horas, além de ter sido fragmentado, quando, na verdade, e de acordo com sua faixa etária, o ideal seria que ele dormisse pelo menos 10 horas no horário noturno e três horas no horário diurno, perfazendo um total de 15 horas nos dois horários, conforme é preconizado na literatura ${ }^{8}, 0$ que não vinha acontecendo. Dessa forma, a sonolência de Junior poderia estar associada a outros fatores como, por exemplo, a falta de sono e interrupção do ciclo do sono.

Seu tempo de sono durante o dia pode ser observado através do Quadro 02 que apresenta 0 quantitavo de horas de sono.

\section{Q uadro 2:}

Demonstrativo do número de horas de sono ( $7 \mathrm{~h}$ às $19 \mathrm{~h}$ )

\begin{tabular}{|c|c|c|}
\hline $\begin{array}{c}\text { Horário em } \\
\text { que dormiu }\end{array}$ & $\begin{array}{c}\text { Horário em que foi } \\
\text { manipulado e } \\
\text { conseqüentemente } \\
\text { acordado }\end{array}$ & $\begin{array}{c}\text { Tempo de } \\
\text { sono }\end{array}$ \\
\hline $08: 30$ & $08: 50$ & $20 \mathrm{~min}$ \\
$10: 25$ & $10: 25$ & - \\
$11: 25$ & $11: 25$ & - \\
$11: 27$ & $11: 30$ & $03 \mathrm{~min}$ \\
$12: 00$ & $12: 00$ & - \\
$12: 03$ & $12: 15$ & $12 \mathrm{~min}$ \\
$12: 27$ & $12: 27$ & - \\
$13: 10$ & $13: 20$ & $10 \mathrm{~min}$ \\
$13: 45$ & $13: 55 *$ & $10 \mathrm{~min}$ \\
$16: 00$ & $14: 30$ & $35 \mathrm{~min}$ \\
& $16: 10$ & $10 \mathrm{~min}$ \\
\hline
\end{tabular}

Fonte: Anotações do diário de campo - *nesse horário a criança não acordou.

Sabe-se que quanto mais uma criança, na idade do Junior, dorme durante o dia, ela dormirá melhor à noite. É comum ouvir das mães que se queixam de seus bebês não dormirem à noite, referirem que durante 0 dia seu filho também dormiu pouco? ${ }^{2}$.

No período observado, isto é, durante o dia, as manipulações foram em número de 20, sendo 12 nos momentos em que ele estava dormindo e em estado de sonolencia, ou seja, oito vezes, enquanto estava acordado, e 12 nos estágios iniciais ou sono propriamente dito. Apesar disso, e devido ao estado de saúde de Junior, que era débil, consideramos alguns desses cuidados indispensáveis: a aspiração das VAS, já que ele estava respirando espontaneamente, porém, com queda de oxigênio e aumento da freqüência respiratória; ausculta pulmonar; coleta de sangue ar terial; exames radiológicos; nebulizações e as trocas de curativos. Tais cuidados se fizeram necessários devido à instabilidade, principalmente, respiratória e a grande drenagem de secreção pela ileostomia, conforme foi comentado anteriormente neste estudo. Ainda assim, muitos desses cuidados impostos a Junior eram indispensáveis, porém, poderiam ter sido agrupados com o intuito de diminuir as interrupções de seu período de sono. Nesse contexto, a interrupção do sono pode ser responsável por diversos danos à criança enferma, pois em qualquer um desses momentos pode comprometer de alguma forma o funcionamento do organismo ${ }^{9}$. Por isso acreditamos que os distúrbios do sono podem produzir sérias conseqüências, podendo desencadear ou exacerbar doenças médicas e psiquiátricas graves.

0 total de horas de sono de Junior, no horário observado, isto é, no $2^{0}$ turno, foi de uma hora e quarenta minutos, fragmentados por 10 interrupções, demonstrando um período de sono totalmente interrompido e com 0 tempo abaixo de suas reais necessidades, 0 que pode traduzir a expressão de cansaço que, frente à constância do stress, o organismo se desorganiza caracterizando-se uma "exaustão" 9 . Outra afirmação que se ajusta ao caso Junior é que, pela persistência de outros estados emocionais desagradáveis, o organismo é afetado, originando as doenças psicossomáticas. Dessa forma, o stress físico e emocional associado à debilidade em seu estado de saúde podem ter sido responsáveis pelo surgimento da mucosite oral observada em Junior.

Junior foi manuseado 20 vezes para realização de procedimentos essenciais e de rotina, tendo esses procedimentos a duração de um minuto a duas horas e trinta minutos. Verificamos que, em média, ele era manuseado, praticamente, a cada vinte e cinco minutos. Resumindo, durante 0 dia foram realizados procedimentos em Junior, com duração mínima de 03 min e máxima 02:30 $h$, ou seja, era praticamente manuseado, em média, a cada vinte e cinco minutos.

A literatura que trata dessa temática9, 10,11,12 aponta que 0 sono é essencial não apenas para restabelecer 0 cansaço físico e mental, mas também é importante para 0 desenvolvimento e crescimento; para cicatrização dos tecidos; para controlar o metabolismo, garantido o equilíbrio das funções orgânicas. Assim, todo e qualquer cuidado que propicie e priorize a manipulação do sono e repouso poderá estar favorecendo a cura, já que estará criando condições e meios de o organismo tornar-se capaz de combater a doença já instalada, impedindo a sua exacerbação e 0 desencadeamento de novos distúrbios para a saúde. 


\section{CONSIDERAÇÕES FINAIS}

Considerando que as necessidades de sono e repouso são mais facilmente percebidas e a manutenção favorece o cliente na aquisição de condições capazes de fazer com que seu organismo responda mais naturalmente às formas de tratamento, acredita-se que o cuidar sob essa óptica implica numa perspectiva além da doença, ou seja, estar atento para a criança e o contexto em que ela está inserida. Ao contrário do que foi observado no cuidado prestado ao Junior, o manuseio desordenado em curto espaço de tempo foi um fator que contribuiu para interrupção do sono, caracterizado pela irritação e a patia apresentadas, condizente com a literatura que trata dessa tematica10,11

0 sono e o repouso de Junior foram interrompidos em intervalos de um a 60 minutos durante a noite e de 25 minutos, em média, durante o dia. Constata-se também que, frente a essa situação, Junior entrava em quadro de exaustão e queda de seu estado geral, evidenciando a necessidade e a privatização do sono e repouso nessas circunstâncias.

0 automatismo na realização de cuidados faz com que os profissionais de UTIP deixem de priorizar alguns desses cuidados prestados à criança, fazendo com que, mais uma vez, a tarefa seja o ponto principal da assistência prestada, o que não é verdade. Se o cliente é 0 alvo central e assume o primeiro lugar no planejamento dessa assistência, o cuidar passa a não mais ser realizado em prol das necessidades individuais dos profissionais e da instituição, mas a favor das necessidades do cliente, favorecendo um cuidado muito mais humanístico e qualificado. Pois, se o cuidado é a essência da enfermagem, então, ele precisa ser a prioridade dos cuidadores ${ }^{5}$.

Este estudo nos remete à reflexão de que o cuidado intensivo em pediatria deve estar voltado para atender às necessidades individuais da criança, utilizando-se da abordagem humanística, que implica na formação de conjuntos, na interdisciplinaridade dos profissionais, buscando a integralidade, a unicidade e a interdependência. Dessa forma, o profissional de enfermagem deve ter responsabilidade máxima com quem está sendo cuidado ${ }^{13}$. Isso deve resultar no desenvolvimento de relações harmoniosas dos membros da equipe entre si e entre cuidadores e a criança, fazendo com que haja cumplicidade no planejamento e desenvolvimento da asssistência no sentido de assegurar a qualidade do cuidado. As medidas que visem à promoção do confor to e que são capazes de facilitar o sono e repouso da criança na UTIP são essenciais, tendo em vista que fazem parte da terapêutica de recuperação dessa criança, porém, devem ser executadas com cautela ${ }^{14}$.

Diante dos resultados deste estudo, no que diz respeito à interrupção do sono de Junior e de suas conseqüências durante a assistência de enfermagem, entendemos que a equipe de profissionais que atua em UTIP, em particular o enfermeiro, deve subsidiar cientificamente, e cada vez mais, a sua assistência, proporcionando bem-estar ao cliente através de um atendimento seguro, responsável e, acima de tudo, compatível com a dignidade de ser humano.

\section{Referências}

1.Cianciarullo TI. Instrumento básico para o cuidar: um desafio para a qualidade da assistência. São Paulo (SP): Atheneu; 1996.

2. Paiva MBA Comunicão no ambiente de terapia Intensiva. Trabalho apresenta no $49^{\circ}$ Congresso Brasileiro de Enfermagem; 1997 dez 7 12; Belo Horizonte (MG), Brasil. Belo Horizonte (MG): ABEn; 1997.

3.Waldow VR. Maneiras de cuidar, maneiras de ensinar: a enfermagem entre a escola e a prática profissional. Porto Alegre (RS): Artes Médicas; 1995.

4. Grande Enciclopédia Médica: roteiro da saúde - repouso. São Paulo (SP): Nova Cultura; 1987.vol. 7.p.26-8.

5. Lemos RCA, Rossi LA. O significado culural atribuido ao Centro de Terapia Intensiva por clientes e seus familiares: um elo entre a beira do abismo e a liberdade. Rev Latino-am Enfermagem 2002 maio/junho; $10(3): 345-57$.

6. Alves 0.0 corpo e as palavras. In: Brauns, HT, organizador. Conversando sobre o corpo. 3a ed. Campinas (SP): Papiros; 1989.

7. Nightingale F. Notas sobre enfermagem: 0 que é e o que não é. São Paulo (SP): Cortez; 1987.

8. Schmitz EM et al. A enfermagem pediatrica e puericultura. São Paulo (SP): Atheneu; 1989.

9. Tuffik S, Nery LE, Bitancout LRA, Polombini L, Bagnoto MC, Moura SMT et al. Como diagnosticar e tratar distúrbios do sono. Rev Bras Medicina 1977 jan/fev; 54(1/2): 12-30. 
10. Sanvito WL. 0 cérebro e suas vertentes. $2^{\text {a }}$ ed. São Paulo (SP): Roca; 1991.

11. Guyton AC. Fisiologia e mecanismo das doenças. 5 âed. Rio de Janeiro (RJ): Guanabara Koogan; 1993.

12. Stefane JMJ Sono na infância In: Schimitz EM. A enfermagem em pediatria e puericultura. São Paulo (SP): Atheneu; 2000.

13. Handem PC, Figueiredo NMA. Imaginário das mães de filhos internados em UTI-Neonatal no pós-parto: contribuição para a enfermagem. Esc Anna Nery Rev Enferm 2004 ago; 8 (2): 211-16.

14. Nascimento MAL. A síndrome da criança membro superior imobilizado para infusão venosa: uma contribuição da semiologia para o cuidado de Enfermagem.[tese de doutorado]. Rio de Janeiro (RJ): Escola de Enfermagem Anna Nery /UFRJ; 1996.

\section{Sobre as Autoras}

\section{Márcia Barbosa de Paiva}

Mestra em enfermagem, gerente da UTIP do Instituto Fernandes Figueira - Fundação Oswaldo Cruz. Docente da Universidade Severino Sombra - Vasouras/RJ

\section{Célia Antunes C. De Souza}

Enfermeira Doutora. Professora Colaboradora no Programa de PósGraduação/Curso de Mestrado em Enfermagem da Universidade do Rio de Janeiro - UNIRIO

\section{Enedina Soares}

Enfermeira Livre Docente. Professora Aposentada da Escola de Enfermagem Alfredo Pinto/UNIRIO. Pesquisadora do CNPq. 